\title{
USE OF TAGUCHI METHOD AND GREY RELATIONAL ANALYSIS TO OPTIMIZE MULTIPLE YARN CHARACTERISTICS IN OPEN-END ROTOR SPINNING
}

\author{
Tanveer Hussain ${ }^{1}$, Farooq Ahmed Arain², Zulfiqar Ali Malik ${ }^{1}$ \\ ${ }^{1}$ Faculty of Engineering \& Technology, National Textile University Faisalabad (37610) Pakistan \\ ${ }^{2}$ Department of Textile Engineering, Mehran University of Engineering \& Technology, Jamshoro Pakistan \\ Corresponding author e-mail: drzulfiqarali70@gmail.com
}

\begin{abstract}
:
Rotor speed and twist per metres (tpm) are two key parameters in open-end rotor spinning of cotton yarns. High spinning productivity can be obtained by keeping the rotor speed high and twist level as low as possible. However, too high rotor speed may result in yarn imperfections and too low twist level may result in lower tenacity yarns. This study aimed at optimising the multiple yarn characteristics in open-end rotor spinning using the Taguchi method and the grey relational analysis. Cotton yarn samples of 30 tex were produced on rotor spinning machine with different twist levels (i.e. 500, 550, 600 and 700 tpm) at different rotor speeds (i.e. 70,000, 80,000, 90,000 and 100,000 rpm) according to the Taguchi design of experiment. Optimal spinning process parameters were determined using the grey relational grade as the performance index. It was concluded that for the cotton fibres and yarn count used in this study, optimum properties of the yarns could be obtained at 90,000 rpm rotor speed and $700 \mathrm{tpm}$.
\end{abstract}

\section{Keywords:}

Rotor yarn, open-end spinning, Taguchi's method, grey relational analysis and optimisation

\section{Introduction}

Cotton yarns may be produced by different spinning methods including ring spinning, rotor spinning, air-jet spinning and friction spinning. Rotor spinning accounts for more than $30 \%$ by volume of the staple yarn produced around the world [1]. Main advantages of rotor spinning in comparison to ring spinning method include less labour force, lower maintenance cost, less number of spare parts, less floor space and lower energy cost because of less machinery involved in the yarn production process. Furthermore, working conditions are usually better in rotor spinning, resulting in better workers' efficiency. Moreover, waste generation for all yarn counts in rotor spinning is significantly less as compared to ring spinning [2].

In terms of quality, rotor yarns have less mass variation, less count variation and imperfections, because of the elimination of drafting waves in the spinning preparatory process. Moreover, rotor spun yarns exhibit higher elasticity as compared to ring spun yarn [3]. Additionally, yarn breakage rate in rotor spinning is lower, which results in improved production as well as quality of the yarn. However, rotor yarns are weaker as compared to ring yarns at equivalent twist levels because of their structural differences. Therefore, higher twist levels are usually used for rotor yarns in order to achieve strength equivalent to that of the ring yarn. Moreover, rotor yarns are somewhat harsher than ring yarns because of high twist levels and structural difference. Actually, in rotor spinning, the fibres are usually wrapped sequentially onto the forming yarn under very low tensions.
Research on various aspects of rotor yarns, including the yarn structure $[4,5]$, the performance of the rotor $[6,7]$, the effect of wrapper fibres in rotor yarn [8], tensile properties of rotor spun yarn [9], effect of rotor speed on yarn quality [10], optimisation of open-end rotor spinning machine parameters [11], torquebalanced rotor yarn [12], effect of twist level and other process parameters on yarn properties, has been reported [13, 14]. No work has so far been reported on simultaneous optimisation of multiple quality characteristics of rotor spun yarn using the Taguchi method and grey relational analysis, although the Taguchi method has been used to study the effect of different spinning process variables $[15,16]$. The grey-Taguchi method has also been used in an attempt to improve the rotor yarn quality [17, 18]. However, the simultaneous optimisation of rotor speed and yarn twist has not been reported previously for multiple yarn characteristics using the grey-Taguchi method, which is the aim of the current study. The Taguchi method offers a systematic approach for the product quality improvement and process optimisation. However, the original Taguchi method could only optimise single response variable. Based on the grey system theory, grey relational analysis is an extension to the original Taguchi method for multi-response optimisation [19, 20].

\section{Experimental}

The properties of cotton fibres used for yarn manufacturing are given in Table 1. Carded slivers from cotton fibres were produced using Rieter blowroom and C-51 carding machine. The homogeneity and levelness of the slivers was further 
increased by giving two passages through RSB-D35 drawing machine. The properties of the resulting sliver are given in Table 2. Total of 16 yarn samples of 30 tex linear density were produced with four different twist levels and four different rotor speeds, on R-40 rotor spinning machine. All the yarns samples were produced according to the Taguchi design of experiments based on the factors and levels given in Table 3. Yarns of 30 tex linear density were produced on R-40 rotor spinning machine according to the Taguchi design of experiments based on the factors and levels given in Table 3. The characteristics of the produced yarns were determined using standard testing methods after proper conditioning of the samples at standard atmospheric conditions. Yarn tenacity (cN/tex) was measured on USTER Tensorapid-4 in accordance with ISO 2062:1993 test method at a gauge length of $500 \mathrm{~mm}$ and an extension speed of $5,000 \mathrm{~mm} / \mathrm{min}$. Twenty tests per package were conducted in standard environment (ISO 139:2005) [26] after conditioning of 48 hours. Thus, total of 200 tests were carried out for each yarn sample. Similarly, USTER Tester-4 was used to determine the yarn unevenness/coefficient of mass variation $(\mathrm{CVm} \%)$, hairiness index and total imperfections (IPI) at a speed of 400 $\mathrm{m} / \mathrm{min}$ according to the ISO 16549:2004 test method. Yarn twist was investigated on a semi-automatic electronic twist tester (Twistronic 2530A made by Mesdan, Italy, according to the ISO 17202:2002 standard test method. This method involves untwisting of the specimen and then retwisting it in the opposite direction until it has regained its original length with automatic double counter check (Schuts) suitable for open-end spun yarns in B mode. Ten packages from each yarn were selected randomly and 20 tests per package were conducted. Thus 200 tests were conducted to get a mean twist value for each yarn.

Table 1. Properties of cotton used in yarn manufacturing.

\section{Results and discussion}

The complete Taguchi orthogonal array and experimental results are given in Table 4. The results show the values of response variables, viz. yarn tenacity (cN/tex), coefficient of mass variation in the yarn $(\mathrm{CVm})$, yarn hairiness and total imperfections (IPI) at various combinations of rotor speed (rpm) and yarn twist per meter (tpm).

\subsection{Grey Relational Analysis}

In the grey relational analysis, the experimental results are first normalised in the range between 0 to 1 because of different measurement units, using equations 1-3. For yarn tenacity, equation (1) is used, because the goal is to maximize yarn tenacity. For CVm, hairiness and IPI, equation (2) is used, because the goal is to minimise these responses. Equation (3) was not used in our study.

For the larger-the-better characteristic,

$$
x_{i}(k)=\frac{y_{i}(k)-\min y_{i}(k)}{\max y_{i}(k)-\min y_{i}(k)}
$$

For the smaller-the-better characteristic,

$$
x_{i}(k)=\frac{\max y_{i}(k)-y_{i}(k)}{\max y_{i}(k)-\min y_{i}(k)}
$$

For the nominal-the-better characteristic,

$$
x_{i}(k)=1-\frac{\left|y_{i}(k)-y_{o b}(k)\right|}{\max y_{i}(k)-\min y_{i}(k)}
$$

\begin{tabular}{|c|c|}
\hline Properties & Measured values \\
\hline Span length $2.5 \%(\mathrm{~mm})$ & 27.55 \\
\hline Span length $50 \%(\mathrm{~mm})$ & 13.08 \\
\hline Uniformity index $(\%)$ & 48.98 \\
\hline Micronaire $(\mu \mathrm{g} / \mathrm{inch})$ & 4.70 \\
\hline Tenacity of fibre bundle $(\mathrm{gm} / \mathrm{tex})$ & 43.44 \\
\hline Trash $(\%)$ & 7.2 \\
\hline Moisture regain $(\%)$ & 7.0 \\
\hline
\end{tabular}

Table 2. Quality parameters of sliver.

\begin{tabular}{|c|c|c|}
\hline Property & Carded sliver & Drawn sliver \\
\hline Weight of sliver (ktex) & 4.05 & 4.0 \\
\hline Coefficient of variation (\%) & 0.886 & 0.18 \\
\hline Mass variation (CVm\%) & 3.32 & 3.27 \\
\hline
\end{tabular}

Table 3. Coded and actual levels of design factors.

\begin{tabular}{|c|c|c|c|c|c|c|}
\hline \multirow{2}{*}{ Factors } & \multirow{2}{*}{ Symbols } & Units & \multicolumn{3}{|c|}{ Coded and Actual Levels } \\
\cline { 4 - 7 } & & & $\mathbf{1}$ & $\mathbf{2}$ & $\mathbf{3}$ & $\mathbf{4}$ \\
\hline Rotor speed & A & rpm & 70,000 & 80,000 & 90,000 & 100,000 \\
\hline Yarn twist & B & tpm & 700 & 600 & 550 & 500 \\
\hline
\end{tabular}


Table 4. Orthogonal array and experimental results.

\begin{tabular}{|c|c|c|c|c|c|c|}
\hline \multirow{3}{*}{ No. } & \multicolumn{2}{|c|}{ Experimental Variables } & \multicolumn{4}{|c|}{ Experimental Results } \\
\hline & $\mathbf{A}$ & B & Y1 & Y2 & Y3 & Y4 \\
\hline & Rotor Speed (rpm) & Yarn Twist (tpm) & Tenacity (cN/tex) & $\mathrm{CVm}$ & Hairiness & IPI \\
\hline 1 & 1 & 1 & 12.2 & 13.0 & 4.93 & 84 \\
\hline 2 & 1 & 2 & 11.3 & 13.0 & 5.08 & 67 \\
\hline 3 & 1 & 3 & 10.5 & 13.0 & 5.13 & 56 \\
\hline 4 & 1 & 4 & 9.5 & 13.1 & 5.26 & 51 \\
\hline 5 & 2 & 1 & 12.8 & 13.1 & 4.78 & 157 \\
\hline 6 & 2 & 2 & 11.6 & 13.5 & 4.97 & 146 \\
\hline 7 & 2 & 3 & 11.0 & 13.8 & 5.15 & 93 \\
\hline 8 & 2 & 4 & 10.1 & 13.4 & 5.22 & 76 \\
\hline 9 & 3 & 1 & 13.3 & 13.0 & 4.48 & 79 \\
\hline 10 & 3 & 2 & 12.0 & 13.1 & 4.58 & 67 \\
\hline 11 & 3 & 3 & 11.5 & 12.9 & 4.44 & 55 \\
\hline 12 & 3 & 4 & 10.1 & 12.8 & 5.23 & 45 \\
\hline 13 & 4 & 1 & 12.7 & 14.1 & 4.86 & 360 \\
\hline 14 & 4 & 2 & 11.7 & 14.4 & 4.95 & 391 \\
\hline 15 & 4 & 3 & 11.1 & 13.9 & 5.33 & 190 \\
\hline 16 & 4 & 4 & 10.3 & 14.4 & 5.33 & 229 \\
\hline
\end{tabular}

where $\max y_{i}(k)$ and $\min y_{i}(k)$ are the largest and smallest values of $y_{i}(k)$, respectively, and $y_{o b}(k)$ is the target of $y_{i}(k)$.

After normalising the experimental results, the grey relational coefficient $\xi_{\mathrm{i}}(k)$ for $\mathrm{y}_{\mathrm{i}}(k)$ to $\mathrm{y}_{0}(k)$ is calculated as follows:

$$
\xi_{i}(k)=\frac{\Delta_{\min }-\Psi_{\max }}{\Delta_{\mathrm{oi}}(k)+\Psi_{\max }}
$$

where $\Delta_{0 \mathrm{i}}=\left\|\mathrm{x}_{0} \mathrm{k}-X_{i} k\right\|$ is the difference of absolute value between $x_{0}(k)$ and $x_{i}(k)$ and $\Delta_{\min }$ and $\Delta_{\max }$ are the minimum and maximum values, respectively, of the absolute differences $\left(\Delta_{0 i}\right.$ ) of all comparing sequences. $\psi$ is a distinguishing coefficient, $0 \leq \Psi \leq 1$. The value of $\Psi$ is to be set to 0.5 to maintain equal weightage of all parameters. The normalised results and grey relational coefficients for each response variable are given in Table 5. On the basis of grey relational coefficients of each response variable, grey relational grade (GRG), $Y_{i}$ is obtained by averaging the grey relational coefficient corresponding to each experiment. The calculated GRGs are given in Table 6.

$$
\mathrm{Y}_{i}=\frac{1}{n} \sum_{i=1}^{0} \xi_{i}(k)
$$

where $\mathrm{n}$ is the number of process responses.

The higher value of the GRG given in Table 6 represents the stronger relational degree between the reference sequence $x_{0}(k)$ and the given sequence $x_{i}(k)$. The reference sequence is the best process response in the experimental results. The higher value of the GRG means that the corresponding process parameter is closer to optimal. Based on this study, the combination of $A 3$ and $B 1$ shows the largest value of the GRG for the factors $A$ and $B$, respectively. The combination of $A 3$ and $B 1$ is treated as the optimal parameter combination of the rotor spinning with best possible results in respective of all the four yarn characteristics. After the grey relational analysis, ANOVA (analysis of variance) was used to determine the parameter that more significantly affects the performance characteristics. The results of ANOVA for the GRG are listed in Table 7 . It is observed that the rotor speed has the highest contribution of about $83.2 \%$ and the yarn twist has less contribution.

\subsection{Confirmation Test}

The estimated GRG $\hat{y}_{\text {using the optimal level of process }}$ parameters can be calculated using equation (6) [22]:

$$
\hat{\mathrm{y}}=\mathrm{y}_{m}+\sum_{i=1}^{q}\left(\overline{\mathrm{y}}_{i}-\mathrm{y}_{m}\right)
$$

where $y_{m}$ is the total mean of the GRG, $\bar{y}_{i}$ is the mean of the grey relational grade at the optimal level and $q$ is the number of process parameters that significantly affect the multiple response characteristics. Based on Eq. (6), the estimated GRG using the optimal process parameters can then be obtained.

Table 8 shows the results of the confirmation experiment using optimal process parameters. As shown in Table 8, yarn tenacity improved from 11.6 to 13.3 , yarn unevenness is reduced from 13.5 to 13.0 , yarn hairiness reduced from 4.97 to 4.48 and yarn imperfections reduced from 146 to 79 . Through grey relational analysis, it is clearly shown that multiple performance characteristics of the rotor yarn, particularly the IPI, are significantly improved.

\section{CONCLUSIONS}

Use of the Taguchi method and grey relational analysis to optimise the rotor spinning parameters for multiple yarn performance characteristics has been reported. A grey relational analysis of the yarn tenacity, unevenness, hairiness and imperfections 
Table 5. Normalised Results and Grey Relational Coefficients.

\begin{tabular}{|c|c|c|c|c|c|c|c|c|c|c|}
\hline \multirow{2}{*}{ No. } & \multicolumn{2}{|c|}{ Factors } & \multicolumn{3}{|c|}{ Normalised Results } & \multicolumn{4}{c|}{ Grey Relational Coefficient } \\
\cline { 2 - 11 } & A & B & $\mathbf{Y}_{1}$ & $\mathbf{Y}_{2}$ & $\mathbf{Y}_{3}$ & $\mathbf{Y}_{4}$ & $\mathbf{Y}_{1}$ & $\mathbf{Y}_{2}$ & $\mathbf{Y}_{3}$ & $\mathbf{Y}_{4}$ \\
\hline 1 & 1 & 1 & 0.7105 & 0.8750 & 0.4494 & 0.8873 & 0.6333 & 0.8000 & 0.4759 & 0.8160 \\
\hline 2 & 1 & 2 & 0.4737 & 0.8750 & 0.2809 & 0.9364 & 0.4872 & 0.8000 & 0.4101 & 0.8872 \\
\hline 3 & 1 & 3 & 0.2632 & 0.8750 & 0.2247 & 0.9682 & 0.4043 & 0.8000 & 0.3921 & 0.9402 \\
\hline 4 & 1 & 4 & 0.0000 & 0.8125 & 0.0787 & 0.9827 & 0.3333 & 0.7273 & 0.3518 & 0.9665 \\
\hline 5 & 2 & 1 & 0.8684 & 0.8125 & 0.6180 & 0.6763 & 0.7917 & 0.7273 & 0.5669 & 0.6070 \\
\hline 6 & 2 & 2 & 0.5526 & 0.5625 & 0.4045 & 0.7081 & 0.5278 & 0.5333 & 0.4564 & 0.6314 \\
\hline 7 & 2 & 3 & 0.3947 & 0.3750 & 0.2022 & 0.8613 & 0.4524 & 0.4444 & 0.3853 & 0.7828 \\
\hline 8 & 2 & 4 & 0.1579 & 0.6250 & 0.1236 & 0.9104 & 0.3725 & 0.5714 & 0.3633 & 0.8480 \\
\hline 9 & 3 & 1 & 1.0000 & 0.8750 & 0.9551 & 0.9017 & 1.0000 & 0.8000 & 0.9175 & 0.8357 \\
\hline 10 & 3 & 2 & 0.6579 & 0.8125 & 0.8427 & 0.9364 & 0.5938 & 0.7273 & 0.7607 & 0.8872 \\
\hline 11 & 3 & 3 & 0.5263 & 0.9375 & 1.0000 & 0.9711 & 0.5135 & 0.8889 & 1.0000 & 0.9454 \\
\hline 12 & 3 & 4 & 0.1579 & 1.0000 & 0.1124 & 1.0000 & 0.3725 & 1.0000 & 0.3603 & 1.0000 \\
\hline 13 & 4 & 1 & 0.8421 & 0.1875 & 0.5281 & 0.0896 & 0.7600 & 0.3810 & 0.5145 & 0.3545 \\
\hline 14 & 4 & 2 & 0.5789 & 0.0000 & 0.4270 & 0.0000 & 0.5429 & 0.3333 & 0.4660 & 0.3333 \\
\hline 15 & 4 & 3 & 0.4211 & 0.3125 & 0.0000 & 0.5809 & 0.4634 & 0.4211 & 0.3333 & 0.5440 \\
\hline 16 & 4 & 4 & 0.2105 & 0.0000 & 0.0000 & 0.4682 & 0.3878 & 0.3333 & 0.3333 & 0.4846 \\
\hline
\end{tabular}

Table 6. Grey Relational Grades.

\begin{tabular}{|c|c|c|c|}
\hline \multirow{2}{*}{ No. } & Rotor Speed (rpm) & Yarn Twist (tpm) & Grey Relational Grade \\
\cline { 2 - 4 } & A & B & GRG \\
\hline 1 & 1 & 1 & 0.6813 \\
\hline 2 & 1 & 2 & 0.6461 \\
\hline 3 & 1 & 3 & 0.6341 \\
\hline 4 & 1 & 4 & 0.5947 \\
\hline 5 & 2 & 1 & 0.6732 \\
\hline 6 & 2 & 2 & 0.5372 \\
\hline 7 & 2 & 3 & 0.5162 \\
\hline 8 & 2 & 4 & 0.5388 \\
\hline 9 & 3 & 1 & 0.8883 \\
\hline 10 & 3 & 2 & 0.7422 \\
\hline 11 & 3 & 3 & 0.8369 \\
\hline 12 & 3 & 4 & 0.6832 \\
\hline 13 & 4 & 1 & 0.5025 \\
\hline 14 & 4 & 2 & 0.4189 \\
\hline 15 & 4 & 3 & 0.4405 \\
\hline 16 & 4 & 4 & 0.3848 \\
\hline
\end{tabular}


Table 7. ANOVA for Grey Relation Grade.

\begin{tabular}{|c|c|c|c|c|c|c|c|}
\hline Source & DF & Seq SS & Adj SS & Adj MS & F & P & Contribution (\%) \\
\hline A, rotor speed & 3 & 0.25738 & 0.25738 & 0.085793 & 61.71 & 0.000 & 83.2 \\
\hline B, yarn twist & 3 & 0.03974 & 0.03974 & 0.013247 & 9.53 & 0.004 & 12.8 \\
\hline Residual error & 9 & 0.01251 & 0.01251 & 0.001390 & & & 4.0 \\
\hline Total & 15 & 0.30963 & & & & & 100 \\
\hline
\end{tabular}

Table 8. Results of the response performances indicating the initial and optimal settings.

\begin{tabular}{|c|c|c|c|}
\hline \multicolumn{4}{|c|}{ Optimal Process Parameters } \\
\hline & Initial settings & Prediction & Experiment \\
\hline Level & A2B2 & A3B1 & A3B1 \\
\hline Yarn tenacity (cN/tex) & 11.6 & 13.12 & 13.3 \\
\hline Yarn unevenness (CVm) & 13.5 & 12.8 & 13.0 \\
\hline Yarn hairiness & 4.97 & 4.46 & 4.48 \\
\hline Yarn imperfections (IPI) & 146 & 97 & 79 \\
\hline Grey relational grade & 0.5372 & 0.867 & 0.8883 \\
\hline \multicolumn{2}{|c|}{ Improvement in grey relational grade: 0.2070} \\
\hline
\end{tabular}

obtained from the Taguchi method can convert optimisation of the multiple performance characteristics into optimisation of a single performance characteristic called the GRG. As a result, optimisation of complicated multiple performance characteristics can be greatly simplified through this approach. It is shown that the cotton multiple yarn characteristics, that is, yarn tenacity, unevenness, hairiness and imperfections are improved together by using the Taguchi method and grey relational analysis. It is shown that multiple cotton yarn characteristics are improved simultaneously by using the Taguchi method and grey relational analysis. Yarn tenacity was improved from 11.6 to $13.3 \mathrm{cN} /$ tex, unevenness decreased from 13.5 to $13.0 \mathrm{CVm}$, hairiness decreased from 4.97 to 4.48 and imperfections decreased from 146 to 79 . The scope of this study is limited to cotton yarn and its production by open-end rotor spinning. Further studies are required for different fibres and their blends and their production by other spinning methods.

\section{References}

[1] Padamanabhan, A.R.: A Comparative Study of the Properties of Cotton Yarns Spun on the DREF-3 and Ringand Rotor-spinning Systems, Journal of Textile Institute, Vol. 80, No. 4, p. 555-562, 1989.

[2] Ozipek, B.: International Textile Workshop, December 2003, Textile Engineering Department, Istanbul Technical University, Istanbul-Turkey.

[3] Jackowski, T.; Chylewska, B.; and Cyniak, D.: Influence of spinning process parameters on strength characteristics of cotton yarn, Fibers \& Textiles in Eastern Europe, V. p.2731, July/ September 2002.

[4] Lord, P. R.; and Grady, P. L.: The Twist Structure of Openend Yarns, Textile Research Journal, V. p. 123, 1976.
[5] Lawrence, C. A.; and Finikopulos, E.: Factor Effecting Changes in the Structure and Properties of Open-end Rotor Yarns, Indian Journal of Fibres \&Textile Research, V.17, p. 201 -208, Dec., 1992.

[6] Lord, P.R.; Muhammad, M. H.; and Ajgaonkar.: The performance of Open -End, Twist less, and ring Yarns in Weft knitted fabrics, Textile Research Journal, V.44, p.405-414, 1974.

[7] Candan, C.; Nergis, U. B.; and Iridag, Y.: Performance of Open-End spun yarns in weft knitted fabrics, Textile Research Journal, V. 70, p. 177-181, 2000.

[8] Koc, E.; Carl, A. L.; and Cherian, l.: Wrapper fibers in Open- end rotor spun yarns: Yarn Properties and Wrapper Fibers, Fibers\& Textiles in Eastern Europe, V. 13, No. 2(50), p. 8-15, April/ June 2005.

[9] Haung $X$.; and Zhu R.: Tensile behavior of rotor spun yarn, Journal of China Textile University (Eng-Ed), V. 7, No.1, p.13-22, 1990.

[10] Gnanasekar, K.; Chellamani, P.; and Karthikeyan. S.: Influence of rotor speed in open-end spinning on yarn quality, Indian Journal of Fiber \& Textile Research, V. 15, p. 164-168, December 1990.

[11] Salhotra, R. K.; and Balasubramanian, P.: An approach to the optimization of Rotor- Spinning machine parameters, Journal of Textile Institute, V. 77, No.2, p.128-138, 1986.

[12] Tao, X. M.; Lo W. K.; and Lau, Y. M.: Torque - balanced singles knitting yarns by unconventional systems. Part I: Cotton rotor spun yarn, Textile Research Journal, V. 67, p. 739-746, 1997.

[13] Sherma, I. C.; Gupta, N. K.; Agrawal, B. R.; and Ataik, $N$. R.: Effect of twist factor and stitch length of open-end spun cotton yarn on properties of rib knitted fabric, Textile Research Journal, V.55, p. 73-81, 1987. 
[14]Xu, D.: Research on Improving the Quality of Rotor Spinning Yarn", Progress in Text Science \& Technology, V. p. 6-13, 2010.

[15] Kumar, A. Ishtiaque, S. M. and Salhotra, K. R.: Analysis of spinning process using the Taguchi method. Part IV: Effect of spinning process variables on tensile properties of ring, rotor and air-jet yarns, Journal of Textile Institute., V. 97, $p$. 38, 2006

[16] Kumar, A. Ishtiaque, S. M. and Salhotra, K. R.: Analysis of spinning process using the Taguchi method. Part III: Effect of spinning process variables on migration parameters of ring, rotor and air-jet yarn, Journal of Textile Institute, V. 97, p. 377, 2006.
[17] Su, T. L. Chen, H. W. Ma, C. M and Lu, C. F.: Improving the Quality of Combed Yarn Spun by OE Rotor Spinning Using the Grey-Taguchi Method, Fibers \& Textiles in Eastern Europe., V. 19, P. 23, (2011).

[18] H. Hasani, S. A. Tabatabaei, and G. Amiri.: Grey Relational Analysis to Determine the Optimum Process Parameters for Open-End Spinning Yarns, J. Eng. Fibers and Fabrics, V. 7, P. 81, (2012).

[19] J. Deng.: Introduction to Grey System Theory, J. Grey System, V. 1, P. 1, (1989).

[20] S. Liu.: The Current Developing Status on Grey System Theory, J. Grey System, V. 2, P. 111, (2007). 